\title{
Chemical Desulfurization of Coal with Hydroiodic Acid
}

\author{
J osé M. Andrés,* Ana C. Ferrando, and Luis Membrado \\ Instituto de Carboquímica, CSIC, Poeta Luciano Gracia 5, 50015-Zaragoza, Spain \\ Received August 10, 1995. Revised Manuscript Received November 29, $1995^{\circledR}$
}

\begin{abstract}
A novel method for the chemical desulfurization of coal in relatively moderate conditions and short times is presented. Using concentrated hydroiodic acid as a desulfurizing agent and microwaves as the energy source, sulfate and pyritic sulfur are completely removed in $10 \mathrm{~min}$. Moreover, for the low-rank coals studied, variable amounts of organic sulfur, up to $70 \%$ in 20 min, can be removed, for a total sulfur (organic + pyritic) elimination greater than $80 \%$. The study of the process shows that time and temperature of the reaction are the main factors affecting the desulfurization process. Experiments with other acids and lower concentrations showed low yields, the special characteristics of the concentrated hydroi odic acid being the driving force of the reaction. Experiments carried out at different microwave power did not show any singular effect of the microwave irradiation on the removal of sulfur.
\end{abstract}

\section{Introduction}

The use of high-sulfur coals for energy production requires a cleaning stage to meet environmental regulations. Most times this cleaning is carried out over the flue gases, but chemical desulfurization has also received attention. Most methods for the chemical desulfurization of coal have relied on the treatment of coal with caustics in oxidizing atmospheres, ${ }^{1,2}$ but this method is difficult to apply to low-rank coals due to the high amount of phenolic and humic materials released during the treatment. ${ }^{3}$

When studying the application of microwaves to coal processes we found that hydroiodic acid allowed sulfur to be removed from the coal when used in a sealed reactor with a reducing atmosphere. In this paper we present this novel and alternativetreatment of coal with hydroi odic acid, which all ows the complete elimination of pyritic sulfur at mild conditions.

\section{Experimental Section}

The reactions were carried out using a microwave digestion equipment (MLS-1200 Mega, Milestone SL) provided with a $500 \mathrm{~mL}$ sealed reactor whose internal parts were made of a fluorinated polymer (TFM, Hoescht AG). According to the manufacturer, the reactor can withstand up to $260{ }^{\circ} \mathrm{C}$ and 60 bar for limited periods of time, with temperature control by means of a thermocouple inside it. The microwave equipment is controlled by an internal microprocessor which allows parameters like reaction time, maximum temperature allowed, venting time, etc. to be set.

All experiments were carried out placing $5 \mathrm{~g}$ of coal in the vessel, adding the required volume of $\mathrm{HI}$ to it (typically 75 $\mathrm{mL}$ of concentrated $\mathrm{HI}$, if not stated otherwise) and bubbling argon for 5 min to obtain an inert atmosphere prior to closing the reactor. As continuous flow of gases through the reactor is not possible, the required volume of hydrogen was added

$\otimes$ Abstract published in Advance ACS Abstracts, J anuary 15, 1996. (1) Meyers, R. A. Coal Desulfurization; Marcel Dekker: New York, 1977

(2) IEA Coal Research. The Problems of Sulphur; Butterworths: London, 1989.

(3) Chriswell, C. D.; Markuszewski, R.; J ewell, D. V. In Processing and Utilization of High-Sulfur Coals IV; Dugan, P. R., Quigley, D. R., Attia, Y. A., Eds.; Elsevier: Amsterdam, 1991; pp 407-424.
Table 1. Composition of the Coals Used in This Work

Sierra de Arcos Pozo Pilar Virgen del Pilar

proximate analysis (\%) moisture ash

elemental analysis (\%)

carbon

hydrogen

nitrogen

sulfur

sulfur forms (\%)

sulfate

pyritic

organic diff

6.4
31.0

40.4
3.2
0.4
6.3

1.6
1.9
2.8

4.8

47.2

6.1

21.9

31.1

2.6

0.5

5.3

46.3

4.2

0.8

9.3

1.4

2.6

0.8

0.3

1.3

8.2

with a gas syringe through a port provided with a rubber septum. After the experiment was complete, the reaction mixture was allowed to cool to $40^{\circ} \mathrm{C}$ and the reactor opened. The reaction mixture was diluted with water and filtered through a Gooch crucible. After washing with water, the crucible was dried in a vacuum oven.

The analysis of the reaction gases poses a big difficulty due to the absorption of hydrogen sulfide in the aqueous solution, so only qualitative analyses of them were carried out using a quadrupole analyzer (QMG-421C, Balzers AG). IR spectra of the solid products (as $\mathrm{KBr}$ discs) were taken with a BOMEM MB-100 FTIR spectrophotometer, averaging 10 scans with a $1 \mathrm{~cm}^{-1}$ resolution.

The base coal for the experiments was a sample (SA) from the Sierra de Arcos mine, located in the Teruel mining district, north zone, in Spain. Other coals used in this work were (PP) from the Pozo Pilar mine, also in the Teruel district, south zone, and (VP) from the Virgen del Pilar mine, in the Mequinenza basin, Zaragoza, Spain. The analyses of thethree coals are shown in Table 1. As the treatment with hydroiodic acid causes the removal of some mineral matter, a soft demineralization of the SA coal was carried out using concentrated hydroiodic acid at $25^{\circ} \mathrm{C}$ for $2 \mathrm{~h}$, which caused a weight loss of $12.76 \%$. The analyses of the resultant product were taken as a base for the calculations, which were done using the "as-received basis" for each product obtained. To avoid false interpretation of the yields obtained, mass balances for each element or form (C, H, S, S forms) were calculated, making the results independent of the behavior of the mineral matter of the coal. Energy balances were also cal culated using heating values (HV) of raw coal and product, according to the following formula: 
Table 2. Results Obtained for the Initial Experiments (Factorial Design)

\begin{tabular}{|c|c|c|c|c|c|c|c|c|c|c|}
\hline time (min) & $\mathrm{H}_{2}(\mathrm{~mL})$ & $\mathrm{V}_{\mathrm{HI}}(\mathrm{mL})$ & $\mathrm{T}_{\max }\left({ }^{\circ} \mathrm{C}\right)$ & yield (\%) & C (\%) & $\mathrm{H}(\%)$ & Stotal $(\%)$ & Spyritic (\%) & Sorganic (\%) & $\mathrm{HV}(\mathrm{kJ} / \mathrm{kg})$ \\
\hline $120^{a}$ & 0 & 50 & 25.0 & 100.0 & 43.5 & 3.3 & 5.7 & 2.3 & 3.4 & 17790 \\
\hline 1 & 1 & 25 & 188.0 & 105.8 & 40.8 & 3.0 & 5.3 & 2.1 & 3.2 & 16626 \\
\hline 1 & 1 & 75 & 117.0 & 102.3 & 42.7 & 3.2 & 6.3 & 2.6 & 3.7 & 17442 \\
\hline 1 & 5 & 25 & 190.0 & 99.1 & 43.7 & 3.2 & 5.2 & 1.7 & 3.4 & 17840 \\
\hline 1 & 5 & 75 & 120.0 & 99.3 & 44.1 & 3.3 & 5.5 & 2.1 & 3.4 & 17836 \\
\hline 3 & 3 & 50 & 230.0 & 86.8 & 48.1 & 3.3 & 3.8 & 0.5 & 3.3 & 19878 \\
\hline 3 & 3 & 50 & 230.0 & 89.1 & 46.7 & 3.2 & 3.9 & 0.4 & 3.5 & 19301 \\
\hline 5 & 1 & 25 & 230.0 & 92.6 & 45.4 & 3.0 & 4.6 & 1.0 & 3.6 & 18301 \\
\hline 5 & 1 & 75 & 230.0 & 93.4 & 44.7 & 3.0 & 4.5 & 0.4 & 4.1 & 18213 \\
\hline 5 & 5 & 25 & 230.0 & 90.3 & 46.3 & 3.0 & 4.8 & 0.8 & 4.1 & 18836 \\
\hline 5 & 5 & 75 & 230.0 & 87.0 & 47.6 & 3.2 & 3.7 & 0.3 & 3.4 & 19657 \\
\hline
\end{tabular}

a Soft demineralization.

$$
\text { energy recovered }=\frac{\mathrm{HV}_{\text {product }} \times \text { weight }_{\text {product }}}{\mathrm{HV}_{\text {coal }} \times \text { weight }_{\text {coal }}}
$$

Concentrated acids used in this work were reagent grade. Concentrated hydroiodic acid (azeotrope at boiling point 127 ${ }^{\circ} \mathrm{C}, \mathrm{d}=1.7 \mathrm{~kg} / \mathrm{L}$, containing $\sim 57 \% \mathrm{HI}$ ) usually contains iodine, which was reduced by addition of small amounts of hypophosphorous acid until discoloration of the remaining solution. The iodine-free acid so obtained was stored under argon.

\section{Results and Discussion}

As far as could be determined, there were no references in the literature to the ability of hydroiodic acid as a desulfurizing agent, the only references found for coal treatment being due to Van Krevelen ${ }^{4}$ about coal liquefaction with hydroiodic acid at high temperatures and hydrogen pressures. The expected effect of the reagent on coal components can be summarized as follows:

(a) Inorganic matter: Most minerals commonly found in coal, like quartz or clays, are relatively insensitive to acid attack, carbonates and sulfates being the only compounds easily removed by acid washing.

Sulfur is present in coal mainly as sulfates and pyrite. It is well-known that sulfates are easily removed from coal by hot acid washing with $3 \mathrm{M}$ hydrochloric acid leaving pyrite unaffected. The removal of pyrite re quires oxidizing or reducing agents like boiling nitric acid. This fact is the basis for the analysis of the sulfur forms in coal according to the ASTM D-2492/90 norm. As iodine-free concentrated hydroiodic acid is a reducing agent, pyrite can be reduced, with evolution of hydrogen sulfide and formation of iodine, until the redox potential of the solution becomes lower than the required for pyrite reduction.

(b) Organic matter: The organic chemistry of hydroiodic acid can be found in organic chemistry textbooks, 5,6 especially for oxygenated functional groups. The most important reactions that can be considered taking place on coal are

cleavage of ethers: $\mathrm{R}-\mathrm{O}-\mathrm{R}^{\prime}+\mathrm{HI} \rightarrow \mathrm{R}-\mathrm{OH}+\mathrm{R}^{\prime}-\mathrm{I}$ cleavage of esters: $\mathrm{R}-\mathrm{COO}-\mathrm{R}^{\prime}+\mathrm{H}_{2} \mathrm{O}+\mathrm{HI}_{\text {cat.am. }} \rightarrow$

$$
\mathrm{R}-\mathrm{COOH}+\mathrm{R}^{\prime}-\mathrm{OH}
$$

(4) Van Krevelen, D. W. Coal, 3rd ed.; Elsevier: Amsterdam, 1993; pp 271-2.

(5) March, J. Advanced Organic Chemistry, International Student Edition; McGraw-Hill International Book Co.: Auckland, New Zealand, 1977.

(6) Allinger, N. L. et al. Organic Chemistry; Worth Publishers Inc: New York, 1971. halogenation of alcohols: $\mathrm{R}-\mathrm{OH}+\mathrm{HI} \rightarrow \mathrm{R}-\mathrm{I}+\mathrm{H}_{2} \mathrm{O}$

reduction of alkyl iodides: $\mathrm{R}-\mathrm{I}+\mathrm{HI} \rightarrow \mathrm{R}-\mathrm{H}+\mathrm{I}_{2}$

In addition, $\mathrm{HI}$ can reduce other functional groups or combination of them, not so abundant in coals like glycols, benzils, or aryl ketones. On the other hand, the reagent is unable to attack aromatics, phenols, and related substances.

Organic sulfur compounds do not behave like their oxygenated counterparts, with sulfides and mercaptans being resistant to cleavage by $\mathrm{HI}$, readily obtained for analogous oxygenated compounds like ethers and alcohols. The most important reaction of $\mathrm{HI}$ with sulfur compounds (in the context of this work) is

$$
\text { reduction of sulfoxides: } \begin{array}{r}
\mathrm{R}-\mathrm{SO}-\mathrm{R}^{\prime}+2 \mathrm{HI} \rightarrow \\
\mathrm{R}-\mathrm{S}-\mathrm{R}^{\prime}+\mathrm{H}_{2} \mathrm{O}+\mathrm{I}_{2}
\end{array}
$$

There is a note of caution, however: most organic reactions involving $\mathrm{HI}$ are carried out using small amounts of reagent dissolved in an organic media, typically acetic acid, and at lower temperatures than those used in the present work.

When applied to low-rank coals, ether and ester cleavage can be expected, yielding phenols and/or aliphatic iodides, which, in some cases, can be dehalogenated. Concerning sulfur-containing functionalities, sulfides and mercaptans usually require strong reducing agents for their reduction, so we cannot infer from literature data if iodine-free concentrated hydroiodic acid could remove significant amounts of these functional groups.

The experimentation was started using a factorial design to obtain information about the process. Trying to simplify the experimentation, three variables were chosen: time of irradiation, hydrogen volume injected, and hydroiodic acid volume. A $1000 \mathrm{~W}$ microwave power for very quick heating was selected, and the maximum temperature allowed was $230^{\circ} \mathrm{C}$, to keep the reaction mixture below the safety limit established by the manufacturer of the reactor. The results given for the analyses of the products obtained are shown in Table 2 and the balances for the elements, sulfur forms, and energy recovered are shown in Figure 1 . The analyses of the reaction gases confirmed that hydrogen sulfide evolves from the chemical treatment of coal with hydroiodic acid, in addition to carbon dioxide arising from the decomposition of carbonate minerals present in the coals tested.

The statistical analysis of the results shows that time of irradiation is the main factor affecting the yield of 


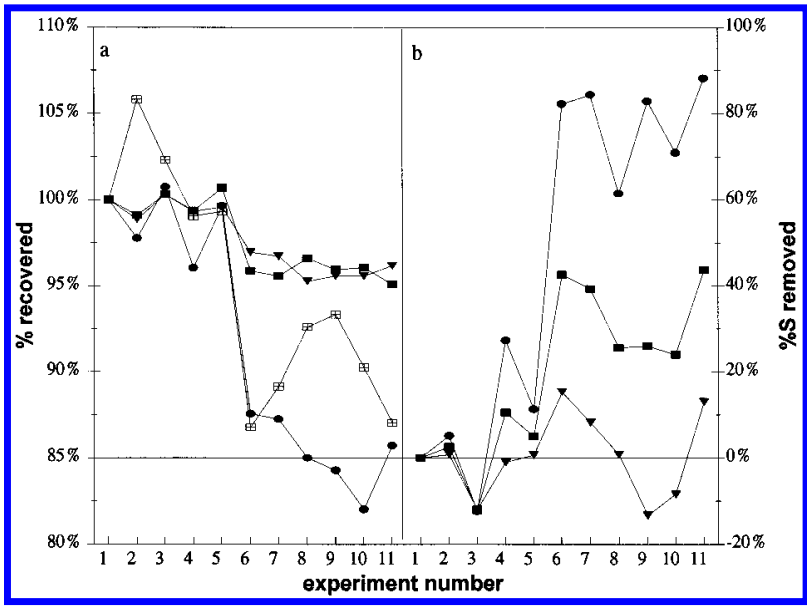

Figure 1. Mass balances for the factorial design experiments: (a) $\square$, yield; $\mathbf{\square}$, carbon; $\bullet$, hydrogen; $\nabla$, energy; (b) $\mathbf{\square}$, total sulfur; $\bullet$, pyritic sulfur; $\boldsymbol{\nabla}$, organic sulfur.

the reaction, mainly due to the desulfurization process. The treatment with hydroiodic acid causes material losses but those of carbon and heating value are small, so the amount of organic matter in the losses should be low. More important losses are found for the total amount recovered and hydrogen content, which we attribute to the attack on the mineral matter of the coal to remove it in a deeper way than that obtained by the soft demineralization performed. As the most important mineral species are silicate minerals like kaol inite and montmorillonite, the attack will destroy their structure, with removal of cations and structural water, which would account for the decrease of the hydrogen content. Sulfur and sulfur forms removal strongly increase with increasing time. As Table 2 shows, short irradiation times did not raise the temperature of the mixture to the levels attained for longer irradiation times, so it is possible to infer theinfluence of temperature in the yield of the desulfurization process. This causes a nonlinear effect, which is shown by the results obtained for the experiments carried out at the center of the design (3 min, $3 \mathrm{~mL}$ of $\mathrm{H}_{2}$, and $50 \mathrm{~mL}$ of $\mathrm{HI}$ ), whose yields are closer to those obtained for the longer time experiments.

The strong and nonlinear effect of time (passing from 1 to 5 min increase the percent of sulfur removed in 28.3 points for total sulfur and 68.0 points for pyritic sulfur) mask the effect of the other variables. As their significance is important to the development of the method, the design was divided into two blocks, one for short times and the other for longer times. The statistical analysis showed a positive effect of hydrogen in both cases, this effect being greater for shorter times. The effect of the volume of acid is related to the heating of the mixture: at short times, lower volumes allow higher temperatures, so the effect is negative, while for longer times, the temperature reaches the maximum allowed and it is the phase change to vapor that causes low volumes of acid to give poorer yields, as the remaining amount of liquid is not enough to completely cover the coal. The effect of this variable can be neglected by carrying out the reaction with appropriate volumes of reagent, so the volume was fixed to $75 \mathrm{~mL}$ for subsequent experiments.

The balances for the sulfur forms show that organic sulfur seems to increase (negative removal) in some experiments. An explanation for this behavior is the

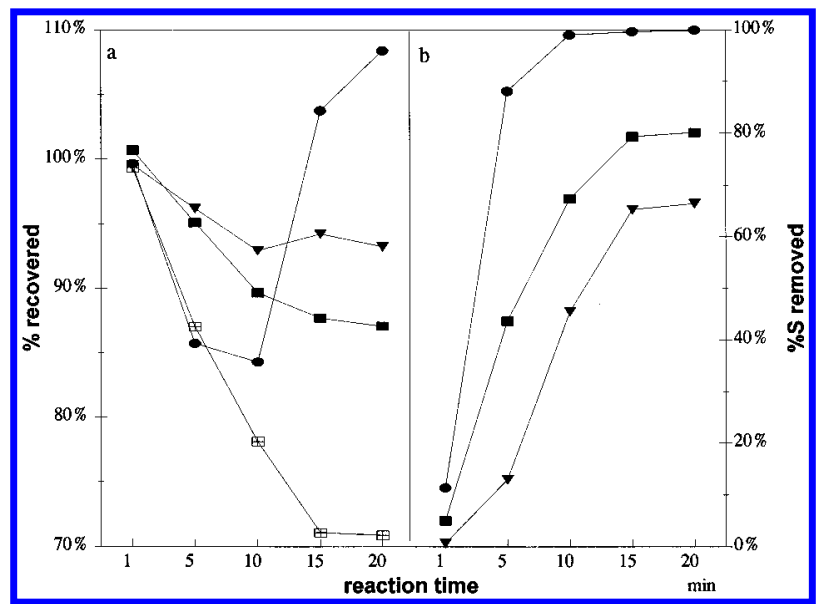

Figure 2. Mass balances of the treatment vs time of irradiation: (a) $\square$, yield; $\mathbf{\square}$, carbon; $\bullet$, hydrogen; $\boldsymbol{\nabla}$, energy; (b) $\mathbf{\square}$, total sulfur; $\bullet$, pyritic sulfur; $\mathbf{\nabla}$, organic sulfur.

Table 3. Effect of Time on the Desulfurization Process

\begin{tabular}{cccccccc}
\hline $\begin{array}{c}\text { time } \\
(\min )\end{array}$ & $\begin{array}{c}\text { yield } \\
(\%)\end{array}$ & $\begin{array}{c}\mathrm{C} \\
(\%)\end{array}$ & $\begin{array}{c}\mathrm{H} \\
(\%)\end{array}$ & $\begin{array}{c}\text { Stotal } \\
(\%)\end{array}$ & $\begin{array}{c}\mathrm{S}_{\text {pyritic }}(\%) \\
(\%)\end{array}$ & $\begin{array}{c}\mathrm{S}_{\text {organic }} \\
(\%)\end{array}$ & $\begin{array}{c}\mathrm{HV} \\
(\mathrm{kJ} / \mathrm{kg})\end{array}$ \\
\hline 1 & 99.3 & 44.1 & 3.3 & 5.5 & 2.1 & 3.4 & 17836 \\
5 & 87.0 & 47.6 & 3.2 & 3.7 & 0.3 & 3.4 & 19657 \\
10 & 78.1 & 50.0 & 3.6 & 2.4 & 0.0 & 2.4 & 21163 \\
15 & 71.1 & 53.7 & 4.8 & 1.7 & 0.0 & 1.6 & 23576 \\
20 & 70.9 & 53.5 & 5.0 & 1.6 & 0.0 & 1.6 & 23400
\end{tabular}

formation of elemental sulfur, which can be detected by extraction with carbon disulfide. The quantitation of this product is difficult and was not attempted. As the purpose of this work is to produce a solid fuel with low sulfur content, the elemental sulfur formed was not considered as removed, though solvent extraction could further reduce the sulfur content of the product.

The results obtained showed that the desulfurization of coal is possible without severe loses of organic matter and energy, so subsequent series of experiments were carried out to establish the effect of longer times, maximum temperature allowed, gaseous environment, and kind of acid on the desulfurization process. For these series, the conditions which yielded the best results, $230{ }^{\circ} \mathrm{C}$ as maximum temperature, $5 \mathrm{~min}$, injection of $5 \mathrm{~mL}$ of hydrogen and $75 \mathrm{~mL}$ of hydroiodic acid, were used as a reference, modifying one variable at a time.

The effect of time in the treatment of the SA coal is shown in Table 3. As time of reaction increases the amount of product recovered decreases, but, compared with the original coal, the product has higher values of $\mathrm{C}, \mathrm{H}$, and $\mathrm{HV}$ with a reduced content of sulfur. The balances for the elements, sulfur forms, and energy recovered are shown in Figure 2. As expected, increasing the time of reaction causes greater losses of product, $C$, and energy recovered, but if time is long enough the reaction seems to be near completion, as shown in the balances for times of 15 and $20 \mathrm{~min}$. This trend is not applicable to hydrogen, as losses of this element increase to a minimum recovery at $10 \mathrm{~min}$ but, for the longer reaction times, there is a small overall gain, with recoveries greater than $100 \%$. As these results take place when removal of organic sulfur is high, it is possible to think that the increase of the hydrogen content is due to hydrogen atoms replacing the sulfur atoms leaving sulfide bonds, but confirmation is necessary. 


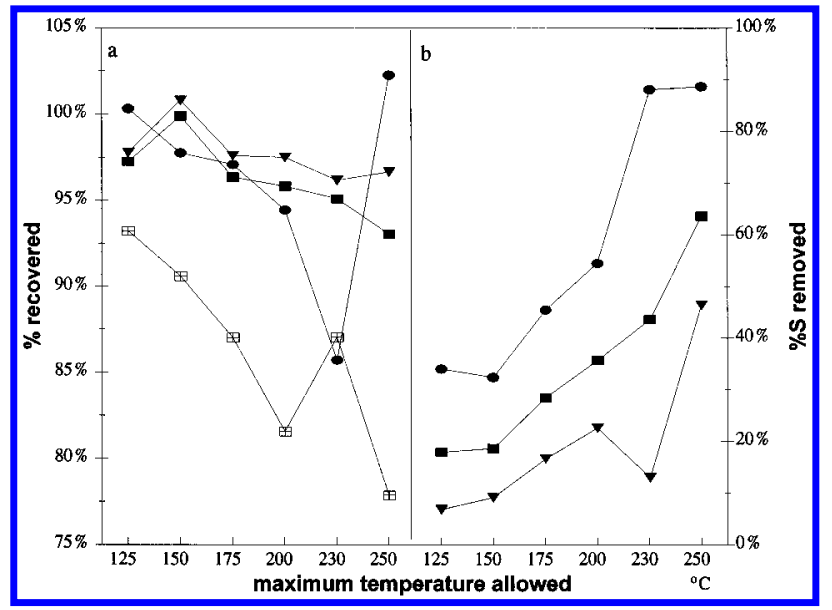

Figure 3. Effect of the maximum temperature on the mass bal ances for the reaction: (a) $\square$, yield; $\boldsymbol{\square}$, carbon; $\bullet$, hydrogen; $\boldsymbol{\nabla}$, energy; (b) $\mathbf{\square}$, total sulfur; $\bullet$, pyritic sulfur; $\boldsymbol{\nabla}$, organic sulfur.

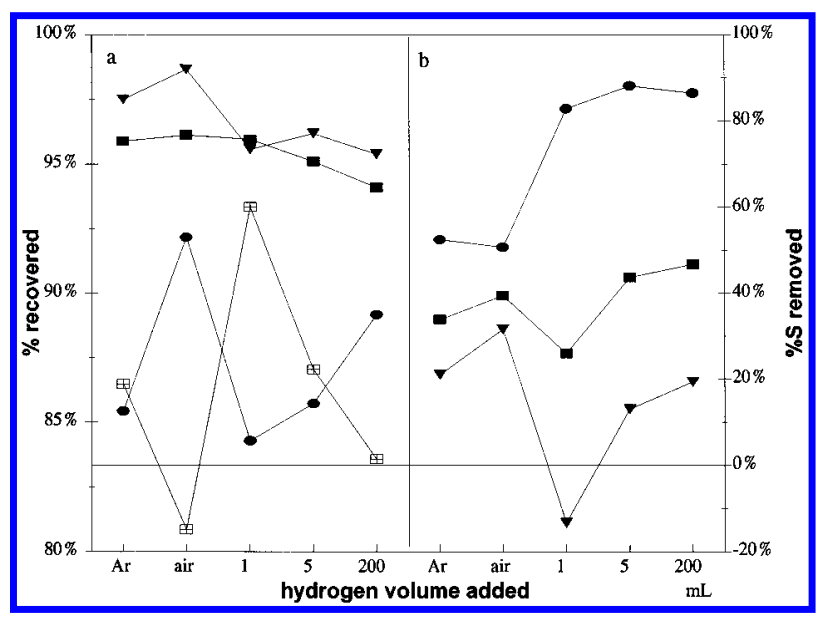

Figure 4. Influence of the gaseous environment on the desulfurization process: (a) $\square$, yield; $\mathbf{\square}$, carbon; $\bullet$, hydrogen; $\boldsymbol{\nabla}$, energy; (b) $\mathbf{\square}$, total sulfur; $\bullet$, pyritic sulfur; $\mathbf{\nabla}$, organic sulfur.

Table 4. Effect of Temperature on the Desulfurization Process

\begin{tabular}{cccccccc}
\hline $\mathrm{T}\left({ }^{\circ} \mathrm{C}\right)$ & $\begin{array}{c}\text { yield } \\
(\%)\end{array}$ & $\begin{array}{c}\mathrm{C} \\
(\%)\end{array}$ & $\begin{array}{c}\mathrm{H} \\
(\%)\end{array}$ & $\begin{array}{c}\text { Stotal } \\
(\%)\end{array}$ & $\begin{array}{c}\mathrm{S}_{\text {pyritic }} \\
(\%)\end{array}$ & $\begin{array}{c}\text { Sorganic } \\
(\%)\end{array}$ & $\begin{array}{c}\mathrm{HV} \\
(\mathrm{kJ} / \mathrm{kg})\end{array}$ \\
\hline 125 & 93.2 & 45.4 & 3.5 & 5.0 & 1.7 & 3.4 & 18655 \\
150 & 90.6 & 48.0 & 3.6 & 5.1 & 1.7 & 3.4 & 19790 \\
175 & 87.0 & 48.2 & 3.7 & 4.7 & 1.5 & 3.2 & 19951 \\
200 & 81.6 & 51.1 & 3.8 & 4.5 & 1.3 & 3.2 & 21269 \\
230 & 87.0 & 47.6 & 3.2 & 3.7 & 0.3 & 3.4 & 19657 \\
250 & 77.9 & 52.0 & 4.3 & 2.7 & 0.3 & 2.3 & 22083
\end{tabular}

The removal of total sulfur depends on the behavior of the sulfur forms. More than $99 \%$ of pyritic sulfur is removed in $10 \mathrm{~min}$ or more of irradiation, which combined with an organic sulfur removal of $64.7 \%$ in the best case ( $20 \mathrm{~min}$ ) allows $80.1 \%$ of the total sulfur of the coal tested to be removed. Lengthening the time of irradiation from 15 to 20 min did not significantly increase the sulfur removal, establishing a limit of desulfurization for the coal tested. This limit for the sulfur removal can be expected to be dependent on the coal treated, yielding good results for coals with pyritic sulfur as the main sulfur form.

The study of the treatment was completed observing the effect of the maximum temperature al lowed while fixing the time of reaction to $5 \mathrm{~min}$. The analyses of the products obtained and the reaction balances are shown in Table 4 and Figure 3, respectively. As expected, increasing the maximum temperature allowed causes an increase in the content of $\mathrm{C}$ and $\mathrm{H}$ of the product, while reducing its sulfur content. As material losses increase so does the organic matter removed, as shown by $\mathrm{C}$ and $\mathrm{H}$ balances. The lower maximum temperatures 125 and $150{ }^{\circ} \mathrm{C}$ did not show significant differences in the yields of the desulfurization process. The next two temperatures 175 and $200{ }^{\circ} \mathrm{C}$ allow a deeper attack to the coal by hydroiodic acid, with greater losses and increased sulfur removal. In these experiments, the removal of sulfur is mainly done by elimination of pyritic sulfur, but the removal of the organic sulfur increases with increasing temperature. Raising the temperature to $230^{\circ} \mathrm{C}$ produces a qualitative leap in the desulfurization yields as much more pyritic sulfur is removed but the elimination of organic sulfur is considerably less than that of the previous experiments, which could be attributed to the transformation of pyritic sulfur to el emental sulfur. Finally, setting the maximum temperature at $250{ }^{\circ} \mathrm{C}$ all ows high yields for the elimination of sulfur, due to an increase in the organic sulfur removal. It is worth noting that hydrogen recovery is higher than $100 \%$, as occurred in the reactions carried out at the longest times. From the data presented here, neither the pyritic sulfur removal nor the organic sulfur removal seems to be simple processes, and further experimentation, including quantification of elemental sulfur, is needed.

The effect of the gaseous environment on yield was established in two ways: first, the experiment taken as a center in the factorial design ( $3 \mathrm{~min}, 3 \mathrm{~mL}$ of $\mathrm{H}_{2}$, and $50 \mathrm{~mL}$ of $\mathrm{HI}$ ) was replicated but with argon alone; second, experiments with air and with $50 \%$ of hydrogen in argon were carried out and compared with those obtained for 1 and $5 \mathrm{~mL}$ of hydrogen. The analytical data and the balances for the reactions are shown in Table 5 and Figure 4, respectively. The use of argon alone produces lower yields than those obtained with hydrogen, but in a different way, as pyritic sulfur removal is greater in hydrogen than in argon alone and, on the contrary, argon alone favors the removal of organic sulfur. A similar effect is obtained with the use of air, which considerably increases the elimination of organic sulfur, though the overall yield is in between those obtained for the experiments with 1 and $5 \mathrm{~mL}$ of hydrogen. The results using air were quite surprising as the liquid phase, once filtered, produced a yellow precipitate which was identified as elemental sulfur. This behavior made the comparison with the other experiments difficult, as the experiment with $1 \mathrm{~mL}$ of hydrogen shows a similar behavior (increase of organic

Table 5. Effect of the Gaseous Environment on the Desulfurization Process

\begin{tabular}{cclccccccc}
\hline time $(\mathrm{min})$ & $\mathrm{H}_{2}(\mathrm{~mL})$ & gas & yield (\%) & $\mathrm{C}(\%)$ & $\mathrm{H}(\%)$ & $\mathrm{S}_{\text {total }}(\%)$ & $\mathrm{S}_{\text {pyritic }}(\%)$ & $\mathrm{S}_{\text {organic }}(\%)$ & $\mathrm{HV}(\mathrm{kJ} / \mathrm{kg})$ \\
\hline 3 & 0 & argon & 86.5 & 48.3 & 3.3 & 4.4 & 1.3 & 3.1 & 20054 \\
5 & 0 & air & 80.9 & 51.7 & 3.8 & 4.3 & 1.4 & 2.9 & 21704 \\
5 & 1 & & 93.4 & 44.7 & 3.0 & 4.5 & 0.4 & 4.1 & 18213 \\
5 & 5 & & 87.0 & 47.6 & 3.2 & 3.7 & 0.3 & 3.4 & 19657 \\
5 & 200 & & 83.6 & 49.0 & 3.5 & 3.6 & 0.4 & 3.3 & 20304
\end{tabular}


Table 6. Effect of Other Acids, HI Concentration, and Iodine Addition on the Desulfurization Process

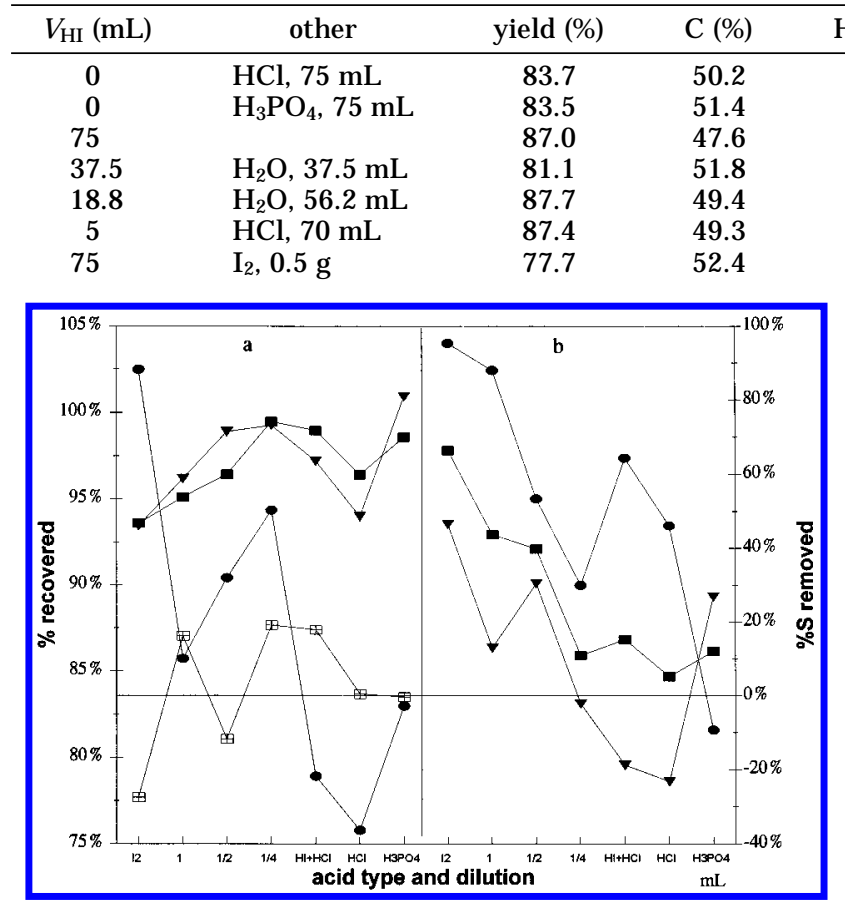

Figure 5. Effect of the kind of acid and concentration on the treatment: (a) $\square$, yield; $\mathbf{\square}$, carbon; $\bullet$, hydrogen; $\mathbf{\nabla}$, energy; (b) $\mathbf{\square}$, total sulfur; $\bullet$, pyritic sulfur; $\mathbf{\nabla}$, organic sulfur.

sulfur content) but elemental sulfur seems to remain in the product, not in solution. Finally, the desulfurization yields obtained for the experiments with hydrogen show that hydrogen is important for the organic sulfur removal, its effect on the elimination of pyritic sulfur being minor.

The last set of experiments were devoted to determine if other acids besides hydroiodic acid could be used and what effect the concentration of this acid has on the desulfurization yields. For comparison purposes concentrated hydrochloric and orthophosporic acids were used, showing desulfurization yields lesser than those obtained with concentrated hydroiodic acid, as shown in Table 6 and Figure 5. The effect of the concentration of the hydroiodic acid was investigated comparing concentrated hydroiodic acid with $1 / 2$ and $1 / 4$ di lutions. Reducing the concentration of the acid to $1 / 2$ produces a reduction in the removal of pyritic sulfur but increases the elimination of the organic sulfur. Further reduction of the concentration of the reagent leads to lower desulfurization yields, with no removal of organic sulfur. In addition to this experiment, two more experiments were carried out to test the behavior of the system. The former tried to establish if hydroiodic acid, an expensive reagent, could be used as a catalyst while maintaining the acidity of the media with hydrochloric acid, a cheaper reagent. While the overall desulfurization yield was not good, pyritic sulfur elimination was significant. The latter experiment added elemental iodine to the mixture to assess if the oxidizing ability of iodine plays a role in the desulfurization process. Results clearly show that iodine enhances sulfur removal, the effect being more pronounced for organic sulfur than for pyritic sulfur. All these experiments demonstrate that the process depends exclusively on the particular behavior of the hydroiodic acid, with acidity, nucleophilicity, and redox potential playing a role in the desulfurization process.

\begin{tabular}{ccccc}
$H(\%)$ & Stotal $_{(\%)}$ & $\mathrm{S}_{\text {pyritic }}(\%)$ & $\mathrm{S}_{\text {organic }}(\%)$ & $\mathrm{HV}(\mathrm{kJ} / \mathrm{kg})$ \\
\hline 3.0 & 6.5 & 1.5 & 5.0 & 19986 \\
3.3 & 6.0 & 3.1 & 3.0 & 21501 \\
3.2 & 3.7 & 0.3 & 3.4 & 19657 \\
3.7 & 4.2 & 1.3 & 2.9 & 21702 \\
3.5 & 5.8 & 1.9 & 3.9 & 20139 \\
3.0 & 5.5 & 1.0 & 4.6 & 19781 \\
4.3 & 2.5 & 0.1 & 2.3 & 21399
\end{tabular}

Table 7. Application of the HI Treatment to Different Coals

\begin{tabular}{lcccccc}
\hline coal & $\begin{array}{c}\text { yield } \\
(\%)\end{array}$ & $\begin{array}{c}\mathrm{C} \\
(\%)\end{array}$ & $\begin{array}{c}\mathrm{H} \\
(\%)\end{array}$ & $\begin{array}{c}\mathrm{S}_{\text {total }} \\
(\%)\end{array}$ & $\begin{array}{c}\mathrm{S}_{\text {pyritic }} \\
(\%)\end{array}$ & $\begin{array}{c}\mathrm{S}_{\text {organic }} \\
(\%)\end{array}$ \\
\hline $\begin{array}{l}\text { Sierra de Arcos } \\
\quad\end{array}$ & & 40.4 & 3.2 & 6.3 & 1.9 & 2.8 \\
$\quad$ raw & & & & & \\
$\quad$ treated & 75.9 & 47.6 & 3.2 & 3.7 & 0.3 & 3.4 \\
$\begin{array}{l}\text { Virgen del Pilar } \\
\quad \text { raw }\end{array}$ & & 46.3 & 4.2 & 9.3 & 0.3 & 8.2 \\
$\quad$ treated & 75.4 & 50.9 & 4.7 & 6.6 & 0.0 & 6.6 \\
$\begin{array}{l}\text { Pozo Pilar } \\
\text { raw }\end{array}$ & & 31.1 & 2.6 & 5.3 & 2.6 & 1.3 \\
$\quad$ treated & 67.7 & 43.1 & 3.6 & 1.4 & 0.0 & 1.4
\end{tabular}

The application of this method to the other two coals tested showed the real abilities of the method. The results, shown in Table 7 , reflect the ability of the method to eliminate pyritic sulfur, with a moderate yield for the removal of the organic sulfur from the coal. Elimination of pyritic sulfur is nearly complete for both coals, but that of organic sulfur represents about onethird of the total organic sulfur. The total sulfur removed differs for the coals tested as the sulfur in PP coal is predominantly inorganic (sulfate + pyritic account for $74.5 \%$ of the total sulfur) while organic sulfur is the main form in VP coal, characteristic of the Mequinenza basin. Therefore, similar values of removal for each sulfur form lead to a $82.5 \%$ yield for PP coal and to a lower $46.1 \%$ for VP coal.

To achieve a deeper understanding of the desulfurization process, infrared spectroscopy was used to obtain correlation spectra, following a cross-correlation technique demonstrated by Honigs et al., ${ }^{7}$ which uses the formula

$$
C_{a b}=\frac{\sum_{n}\left(a_{i}-\bar{a}\right)\left(b_{i}-\bar{b}\right)}{\sum_{n}\left(b_{i}-\bar{b}\right)^{2}}
$$

Briefly, this technique calculates the value where $a_{i}$ is the absorbance of the sample $i$ at a given wavel ength and $b_{i}$ is the amount of the compound or property value to be correlated with. Doing so for all the wavelengths gives a calculated correlation spectrum for the compound or property considered. The cross-correlation spectra for total, pyritic, and organic sulfur are shown in Figure 6, together with the spectra of pure kaolinite and pyrite minerals, for comparison purposes. The interpretation of the correlation spectra is simple: positive values for the absorption bands imply that the behavior of the compound which produces them is similar to that of the compound tested, with negative values indicating the opposite. Applied to the reaction studied, positive values reflect compounds disappearing during the desulfurization process, while negative val-

(7) Honigs, D. E.; Hieftje, G. M.; Hirschfeld, T. Appl. Spectrosc. 1984, 38 (3), 317-322. 


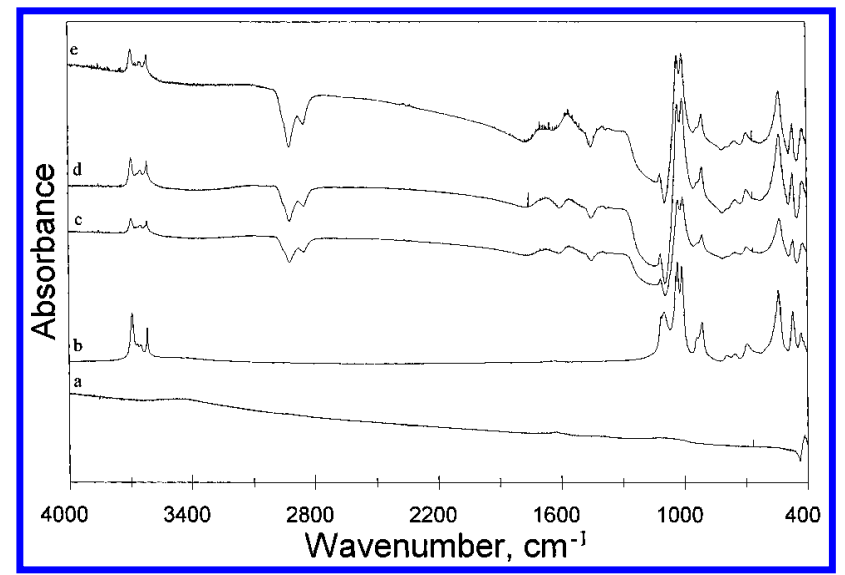

Figure 6. From the bottom up, IR spectra of pyrite (a) and kaolinite (b), and cross-correlation IR spectra for total sulfur (c), pyritic sulfur (d), and organic sulfur (e).

ues show the appearance of new compounds as the reaction proceeds and sulfur is removed. The analysis of the correlation spectra can be divided in two parts: the absorption bands bel ow $1100 \mathrm{~cm}^{-1}$ together with the small bands near $3600 \mathrm{~cm}^{-1}$ agree with those obtained for kaolinite, showing the destruction of this mineral phase during the desulfurization process, yielding a new phase to which the band located at $1100 \mathrm{~cm}^{-1}$ can be assigned. The other part of the correlation spectra, from 1100 to $3300 \mathrm{~cm}^{-1}$, shows the evolution of the organic matter during the treatment. The most important change is the strong, wide band appearing between 1150 and $1250 \mathrm{~cm}^{-1}$, which can be attri buted to ali phatic and aromatic hydroxyl groups arising from the hydrolysis of ester and ether bonds, catalyzed by hydroiodic acid. The other change corresponds to the intensity increase observed for the absorption bands at 1440, 2900, and $2950 \mathrm{~cm}^{-1}$, corresponding to vibration modes of $\mathrm{CH}_{2}$ and $\mathrm{CH}_{3}$ groups, indicating an increase of the abundance of this groups with the treatment. As said above, the chemistry of the treatment is not well-defined and considerable effort is needed to clarify it. What is important, in addition of the sulfur removal, is that the hydrolysis of the ester and ether bonds could lead to the fragmentation of the macrostructure of coal, yiel ding fragments of smaller molecular weight extractable by organic solvents. We are now testing this behavior, of great importance for a mild liquefaction process.

The results presented allow us to conclude that chemical desulfurization of coals with hydroiodic acid is possible and that this desulfurization process mainly removes pyritic sulfur, together with moderate amounts of organic sulfur. Sulfur is removed as hydrogen sulfide, though elemental sulfur is also obtained but not separated from the product. Future work will deal with model compounds to assess the ability of hydroiodic acid to remove different kind of sulfur bonds, including pyritic sulfur, and to try to establish the mechanisms that play a role in the overall process.

Acknowledgment. The work shown here was funded by the European Coal and Steel Community (ref. 9220EC/759) and Spanish CICYT (ref. AMB92-1221-CE). A patent has been applied for the treatment described in the paper.

EF9501612 